\title{
Safety and Tolerability Results from the PILLAR Study: A Phase IV, Double-Blind, Randomized, Placebo-Controlled Study of Mirabegron in Patients $\geq 65$ years with Overactive Bladder-Wet
}

\author{
Sender Herschorn ${ }^{1}$ (D) David Staskin ${ }^{2} \cdot$ Carol R. Schermer $^{3} \cdot$ Rita M. Kristy ${ }^{3} \cdot$ Adrian Wagg $^{4}$
}

Published online: 28 July 2020

(c) The Author(s) 2020

\begin{abstract}
Background In older patients with overactive bladder (OAB), mirabegron, a $\beta_{3}$-adrenoreceptor agonist, represents an alternative treatment that may have a favorable risk-benefit profile.

Objectives Our objective was to further examine the safety and tolerability of mirabegron versus placebo treatment in patients aged $\geq 65$ years with OAB-wet.

Methods We conducted a 12-week, double-blind, randomized, placebo-controlled phase IV study to compare mirabegron with placebo. Community-dwelling patients aged $\geq 65$ years with $\mathrm{OAB}$-wet (one or more incontinence episode and three or more urgency episodes, and an average of eight or more micturitions/24 h over a 3-day diary) were randomized to receive placebo or mirabegron $25 \mathrm{mg} /$ day (optional dose escalation to $50 \mathrm{mg}$ /day at week 4 or 8 ). Safety analyses were performed for adverse events (AEs) and vital signs on all randomized patients who received one or more dose of study drug.

Results Treatment-emergent AEs (TEAEs), the majority mild or moderate in severity, were reported in $39.4 \%$ of placebo patients and 44.2 and $49.8 \%$ of those who received mirabegron $25 \mathrm{mg}$ or $50 \mathrm{mg}$, respectively. The most common TEAEs in mirabegron-treated patients were urinary tract infection, headache, and diarrhea. The incidence of TEAEs was slightly higher in mirabegron patients aged $\geq 75$ years than in those aged $<75$ years. There were no clinically meaningful differences in changes in vital signs from baseline to end of treatment for any treatment group, and no differences were observed between mirabegron and placebo treatment groups. TEAEs tended to occur early post exposure and were not dose related.

Conclusions Mirabegron treatment was well-tolerated in older adults with OAB-wet. Safety and tolerability were consistent with the known mirabegron safety profile.
\end{abstract}

Trial Registration This study is registered at ClinicalTrials.gov: NCT02216214.

\section{Introduction}

Electronic supplementary material The online version of this article (https://doi.org/10.1007/s40266-020-00783-w) contains supplementary material, which is available to authorized users.

Sender Herschorn

s.herschorn@utoronto.ca

1 Department of Surgery/Urology, Sunnybrook Health Sciences Centre, University of Toronto, 2075 Bayview Avenue, MG408, Toronto, Ontario M4N 3M5, Canada

2 Division of Urology, St Elizabeth's Medical Center, 736 Cambridge Street, Brighton, MA, USA

3 Astellas Pharma Global Development, Inc., 1 Astellas Way, Northbrook, IL 60062, USA

4 Department of Medicine, University of Alberta, 1-198 Clinical Sciences Building, 1135083 Avenue, Edmonton, $\mathrm{AB}$, Canada
The prevalence of overactive bladder $(\mathrm{OAB})$ - a symptom complex of storage lower urinary tract symptoms characterized by the presence of urinary urgency - increases with age, with a prevalence rate in those aged $\geq 65$ years double that in those aged $\leq 45$ years [1-4]. Patients with OAB are often treated with antimuscarinics, but these are commonly associated with adverse events (AEs) that limit adherence, such as dry mouth and constipation [5]. The incidence of AEs tends to increase with older age, and AEs experienced with antimuscarinics may be more pronounced in older patients $[6,7]$. In older patients receiving multiple medications, use of antimuscarinics may result in considerable anticholinergic burden [5, 8-11].

Mirabegron, a $\beta_{3}$-adrenoreceptor agonist, represents an alternative treatment for $\mathrm{OAB}$ and potentially has a more 


\section{Key Points}

Mirabegron treatment was well-tolerated in older adults with overactive bladder (OAB)-wet; few serious adverse events (SAEs) were reported, and only two (both in the placebo group) were considered to be drug related by the investigator; there were no mirabegron-related SAEs.

Treatment-emergent adverse effects did not appear to be either dose or age related, and no new safety signal was seen in this exclusively older population.

There were no clinically meaningful differences in changes in vital signs from baseline to end of treatment for any treatment group, and no differences were observed between the mirabegron and placebo treatment groups.

The findings reported provide further evidence for the overall safety and tolerability profile for mirabegron in patients aged $\geq 65$ years with OAB-wet.

favorable benefit-to-risk profile than antimuscarinics in older patients [8, 12-14]. In phase III trials of mirabegron, the incidence of dry mouth and constipation was similar to that seen with placebo $[15,16]$. Mirabegron and antimuscarinics are both recommended as first-line pharmacotherapy in EU and US guidelines [17, 18].

PILLAR was the first study of mirabegron specifically designed to assess efficacy and safety in patients aged $\geq 65$ years with OAB-wet. In the primary analysis, improvements in bladder diary parameters were observed for mirabegron versus placebo; safety and tolerability were in line with the mirabegron safety profile [19].

As older patients with OAB tend to have high levels of comorbidities [6], it is particularly important to understand the in-depth safety profile of medications in this population. Cardiovascular risks are of particular concern because they increase with age, and people with OAB are more likely to have cardiovascular comorbidities than are those without OAB [20].

Consequently, this paper aims to provide an in-depth examination of the safety and tolerability of mirabegron versus placebo in the PILLAR study, beyond that explored in the primary paper.

\section{Methods}

PILLAR was a double-blind, randomized, placebo-controlled, parallel group, multicenter, 12-week phase IV study (NCT02216214) designed to evaluate mirabegron in a flexible dosing regimen compared with placebo. The study was conducted between October 2014 and December 2017 at 103 sites in the USA and Canada and was powered to detect a difference between placebo and mirabegron on incontinence and micturition frequency.

\subsection{Patients}

The primary paper was published recently and includes detailed methods for the study [19]. Community-dwelling patients aged $\geq 65$ years with $\mathrm{OAB}$-wet (one or more incontinence episode and three or more urgency episodes, and an average of eight or more micturitions/24 h over a 3-day diary) were randomized $1: 1$ to receive placebo or mirabegron. The mirabegron/placebo dose was started at $25 \mathrm{mg} /$ day, the recommended starting dose in Canada and the USA, but the dose could be increased to $50 \mathrm{mg} /$ day at week 4 or 8 based on individual efficacy/tolerability and investigator discretion. Full inclusion/exclusion criteria are shown in Table 1 in the Electronic Supplementary Material (ESM). Institutional review board/independent ethics committeeapproved written informed consent was obtained from all participants or their legally authorized representatives before any study-related procedures were carried out.

\subsection{Safety Analyses}

Safety evaluations included vital signs, AE recording, clinical laboratory assessments, and physical examinations. Vital signs were measured at all in-office study visits and by home blood pressure monitoring prior to each visit, and electrocardiograms (ECG) were conducted at each study visit.

An AE of hypertension was recorded if one of the following criteria was met on two or more consecutive visits:

1. If the average systolic blood pressure (SBP) was $>140 \mathrm{mmHg}$ and/or the average diastolic blood pressure (DBP) was $>90 \mathrm{mmHg}$ at two consecutive visits after baseline in patients who were normotensive (average SBP $<140 \mathrm{mmHg}$ and average $\mathrm{DBP}<90 \mathrm{mmHg}$ ) at baseline.

2. If the average SBP was increased $>20 \mathrm{mmHg}$ and/or the average DBP was increased $>10 \mathrm{mmHg}$ at two consecutive visits as compared with baseline (visit 3 ) in patients with hypertension at baseline (visit 3).

3. If treatment with antihypertensive drugs was initiated for treatment of hypertension or if the dose of prior antihypertensive drugs was increased due to an increase in blood pressure.

The investigator could report an AE of "increased" blood pressure if the above conditions were not met but a high blood pressure was recorded. An AE of tachycardia was considered if resting heart rate (pulse rate) was $>100 \mathrm{bpm}$. 
For home blood pressure monitoring, validated devices and detailed operating instructions for measuring blood pressure and pulse rate were provided to patients. Patients measured their blood pressure and pulse rate three times, each about 2 min apart for 3 days prior to each study visit. Measurements were recorded in the morning before breakfast prior to taking study drug, and again in the evening, and were documented in electronic diaries. Patients were instructed to have a 30-min rest after exercise or smoking or intake of caffeine or alcohol, prior to taking a measurement. An AE of tachycardia should have been considered if the mean morning or afternoon pulse rate in the resting state from patient-reported measurements at home over the last 3 diary days was $>100 \mathrm{bpm}$. For home-based monitoring, any extreme values outside of normal ranges for the vital sign (SBP 60-220 mmHg; DBP 30-140 mmHg; pulse rate $30-250 \mathrm{bpm}$ ) were excluded for vital sign parameter calculations.

AEs were collected throughout the study to week 16 (30 days after the end of treatment [EoT]), at which time patients received a follow-up phone call. Patients reported AEs in response to open-ended questioning. A treatmentemergent AE (TEAE) was defined as one that started or worsened from first study medication dose until 30 days after EoT. TEAEs were coded using the Medical Dictionary for Regulatory Activities (MedDRA) v20.1 [21]. The severity and likely causal relationship to the study drug were determined by the study investigator. An AE was considered a serious $\mathrm{AE}$ (SAE) if it resulted in death, was life-threatening, required inpatient hospitalization, or led to prolongation of existing hospitalization.

Physical examinations were conducted, laboratory parameters obtained, and post-void residual (PVR) volume assessed (by ultrasonography/bladder scan) at screening and EoT. Events relating to urinary retention were aggregated for the safety analysis.

An overview of the main TEAEs is presented in the primary paper [19]. TEAEs were assessed overall and in each age subgroup ( $<75$ and $\geq 75$ years). TEAEs of special interest included cardiovascular events, blood pressure, myocardial infarction, stroke, serious arrhythmias, urinary tract infection (UTI), acute urinary retention, benign prostatic obstruction (BPO) requiring surgery, and cognitive impairment as determined by the Montreal Cognitive Assessment score (results presented in a separate manuscript [22]). Cardiovascular events were assessed by an independent adjudication committee.

Safety analyses were performed for AEs and vital signs on the safety analysis set, which included all randomized patients who received one or more dose of study drug. No inferential comparison between treatment groups was performed.

\section{Results}

\subsection{Participants}

Of 2380 patients screened, 443 were randomized to placebo and 445 to mirabegron; one patient in the placebo group did not receive treatment (Table 1; Fig. 1). Of patients who discontinued treatment, ten $(2.3 \%)$ in the placebo arm, six $(2.7 \%)$ in the mirabegron $25 \mathrm{mg}$ arm, and two $(0.9 \%)$ in the mirabegron $50 \mathrm{mg}$ arm discontinued because of an AE.

Of the 887 randomized patients who received one or more dose of study drug, $72.3 \%$ were female, $79.5 \%$ were White, and $28.1 \%$ were aged $\geq 75$ years. Nearly half of patients who were randomly assigned to mirabegron increased their dose to $50 \mathrm{mg}$ (219 [49.2\%] patients). There were no notable differences between the mirabegron group and the placebo group in demographic characteristics at baseline. At baseline, patients had a mean \pm standard deviation $8.2 \pm 5.7$ comorbid conditions and $94.5 \%$ were receiving one or more concomitant medication. The mean number of concomitant medications taken by patients was $6.5 \pm 4.7$. The most frequently reported comorbid conditions were hypertension (56.6\%) and osteoarthritis (36.2\%).

\subsection{Safety}

Overall, 327 TEAEs were reported by 174 (39.4\%) patients receiving placebo, 169 TEAEs were reported by 100 (44.2\%) patients receiving mirabegron $25 \mathrm{mg}$, and 206 TEAEs were reported by 109 (49.8\%) patients receiving mirabegron $50 \mathrm{mg}$. In total, 57 (12.9\%), 47 (20.8\%), and 37 (16.9\%) TEAEs were deemed possibly or probably related to study drug, respectively (Table 2). The majority of TEAEs in all treatment groups were mild or moderate in severity, and no TEAEs resulted in death. The most common TEAEs in mirabegron-treated patients were UTI, headache, and diarrhea. Serious TEAEs were reported in 12 (2.7\%), 7 (3.1\%), and 8 (3.7\%) patients receiving placebo, mirabegron $25 \mathrm{mg}$, and mirabegron $50 \mathrm{mg}$, respectively. Two placebo-treated patients experienced serious TEAEs (cerebrovascular accident and transient ischemic attack) that were considered drug related as assessed by the investigator at the time; there were no mirabegron-related SAEs. Overall, TEAEs that led to study discontinuation were reported in 28 patients (14 [3.2\%], 8 [3.5\%], and 6 [2.7\%] receiving placebo, mirabegron $25 \mathrm{mg}$, and mirabegron $50 \mathrm{mg}$, respectively).

The incidence of TEAEs was higher in mirabegron patients aged $\geq 75$ years than in those aged $<75$ years (Table 2). For TEAEs that occurred in $\geq 2 \%$ of patients, UTI, vomiting, fatigue, fall, hypertension, dysuria, and hyperglycemia occurred more frequently in patients aged $\geq 75$ years than in those aged $<75$ years. The incidence 
Table 1 Baseline characteristics (safety analysis set)

\begin{tabular}{|c|c|c|c|c|}
\hline \multirow[t]{2}{*}{ Characteristics } & \multirow[t]{2}{*}{ Placebo $(n=442)$} & \multicolumn{3}{|l|}{ Mirabegron } \\
\hline & & $25 \mathrm{mg}(n=226)$ & $50 \mathrm{mg}(n=219)$ & Total $(n=445)$ \\
\hline Female sex & $324(73.3)$ & $168(74.3)$ & $149(68.0)$ & $317(71.2)$ \\
\hline Age (years) & $71.9 \pm 6.0$ & $71.6 \pm 5.8$ & $71.7 \pm 5.2$ & $71.7 \pm 5.5$ \\
\hline Age $\geq 75$ years & $124(28.1)$ & $66(29.2)$ & $59(26.9)$ & $125(28.1)$ \\
\hline $\mathrm{BMI}\left(\mathrm{kg} / \mathrm{m}^{2}\right)$ & $30.2 \pm 6.4$ & $29.2 \pm 6.0$ & $30.1 \pm 6.6$ & $29.7 \pm 6.3$ \\
\hline \multicolumn{5}{|l|}{ Category } \\
\hline$<25$ & $91(20.6)$ & $60(26.5)$ & 48 (21.9) & $108(24.3)$ \\
\hline$\geq 25$ to $<30$ & $150(33.9)$ & $84(37.2)$ & $73(33.3)$ & $157(35.3)$ \\
\hline$\geq 30$ & $201(45.5)$ & $82(36.3)$ & $98(44.7)$ & $180(40.4)$ \\
\hline \multicolumn{5}{|l|}{ Race } \\
\hline White & $357(80.8)$ & $151(66.8)$ & $197(90.0)$ & $348(78.2)$ \\
\hline Black or African American & $25(5.7)$ & $16(7.1)$ & $17(7.8)$ & $33(7.4)$ \\
\hline Asian & $54(12.2)$ & $58(25.7)$ & $1(0.5)$ & $59(13.3)$ \\
\hline Other & $6(1.4)$ & $1(0.4)$ & $4(1.8)$ & $5(1.1)$ \\
\hline \multicolumn{5}{|l|}{ Country } \\
\hline USA & $389(88.0)$ & $215(95.1)$ & $170(77.6)$ & $385(86.5)$ \\
\hline Canada & $53(12.0)$ & $11(4.9)$ & $49(22.4)$ & $60(13.5)$ \\
\hline \multicolumn{5}{|c|}{ Medical history, most frequent conditions $\mathrm{s}^{\mathrm{a}}$} \\
\hline Hypertension & $243(55.0)$ & $134(59.3)$ & $125(57.1)$ & $259(58.2)$ \\
\hline Osteoarthritis & $173(39.1)$ & $60(26.5)$ & $87(39.7)$ & $147(33.0)$ \\
\hline Hypertonic bladder ${ }^{\mathrm{b}}$ & $145(32.8)$ & $86(38.1)$ & $72(32.9)$ & $158(35.5)$ \\
\hline Gastroesophageal reflux disease & $135(30.5)$ & $54(23.9)$ & $77(35.2)$ & $131(29.4)$ \\
\hline \multicolumn{5}{|c|}{ Concomitant non-OAB medications, most frequent } \\
\hline Vitamins & $208(47.1)$ & $95(42.0)$ & $114(52.1)$ & $209(47.0)$ \\
\hline Analgesics & $201(45.5)$ & $100(44.2)$ & $110(50.2)$ & $210(47.2)$ \\
\hline Lipid-modifying agents & $190(43.0)$ & $93(41.2)$ & $99(45.2)$ & $192(43.1)$ \\
\hline
\end{tabular}

Data are presented as mean \pm standard deviation or $N(\%)$ unless otherwise indicated. Safety analysis set: all randomized subjects who received one or more dose of study medication. Reprinted from Wagg et al. [19] with permission from Elsevier

$B M I$ body mass index, $O A B$ overactive bladder

${ }^{\mathrm{a}}$ By preferred term

${ }^{\mathrm{b}}$ Worsening $\mathrm{OAB}$

of dizziness was higher in patients aged $<75$ years than in those aged $\geq 75$ years.

TEAEs by titration occurring in $\geq 5 \%$ of patients in any dose group are shown in Table 3. TEAEs tended to occur early and were not dose related. TEAEs were reported in $44.2 \%$ of the mirabegron $25 \mathrm{mg}$ group and, in the mirabegron $50 \mathrm{mg}$ group prior to titration, in $23.4 \%$ at week 4 and $33.3 \%$ at week 8 . Post-titration, in the mirabegron $50 \mathrm{mg}$ group, TEAEs were reported in $35.9 \%$ at week 4 and $14.8 \%$ at week 8 .

\subsubsection{Treatment-Emergent Adverse Events of Special Interest}

According to the independent cardiovascular event adjudication committee, four patients experienced an Antiplatelet Trialists' Collaboration (APTC)/major adverse cardiovascular event (MACE). Of the four APTC/MACE patients, a nonfatal myocardial infarction was reported for one patient in the mirabegron $50 \mathrm{mg}$ group and nonfatal stroke was reported in three patients (two receiving placebo and one receiving mirabegron $50 \mathrm{mg}$ ). Non-APTC/MACE was reported in two patients, both in the placebo group: one transient ischemic attack (mentioned previously) and one arrhythmia (no evidence of ischemia and not considered serious).

A TEAE of increased blood pressure was reported for two patients in the placebo group and five patients in the mirabegron total group (two receiving mirabegron $25 \mathrm{mg}$, three receiving mirabegron $50 \mathrm{mg}$ ). A TEAE of increased heart rate was reported for two patients in the mirabegron total group (one receiving mirabegron $25 \mathrm{mg}$, one receiving mirabegron $50 \mathrm{mg}$ ). 


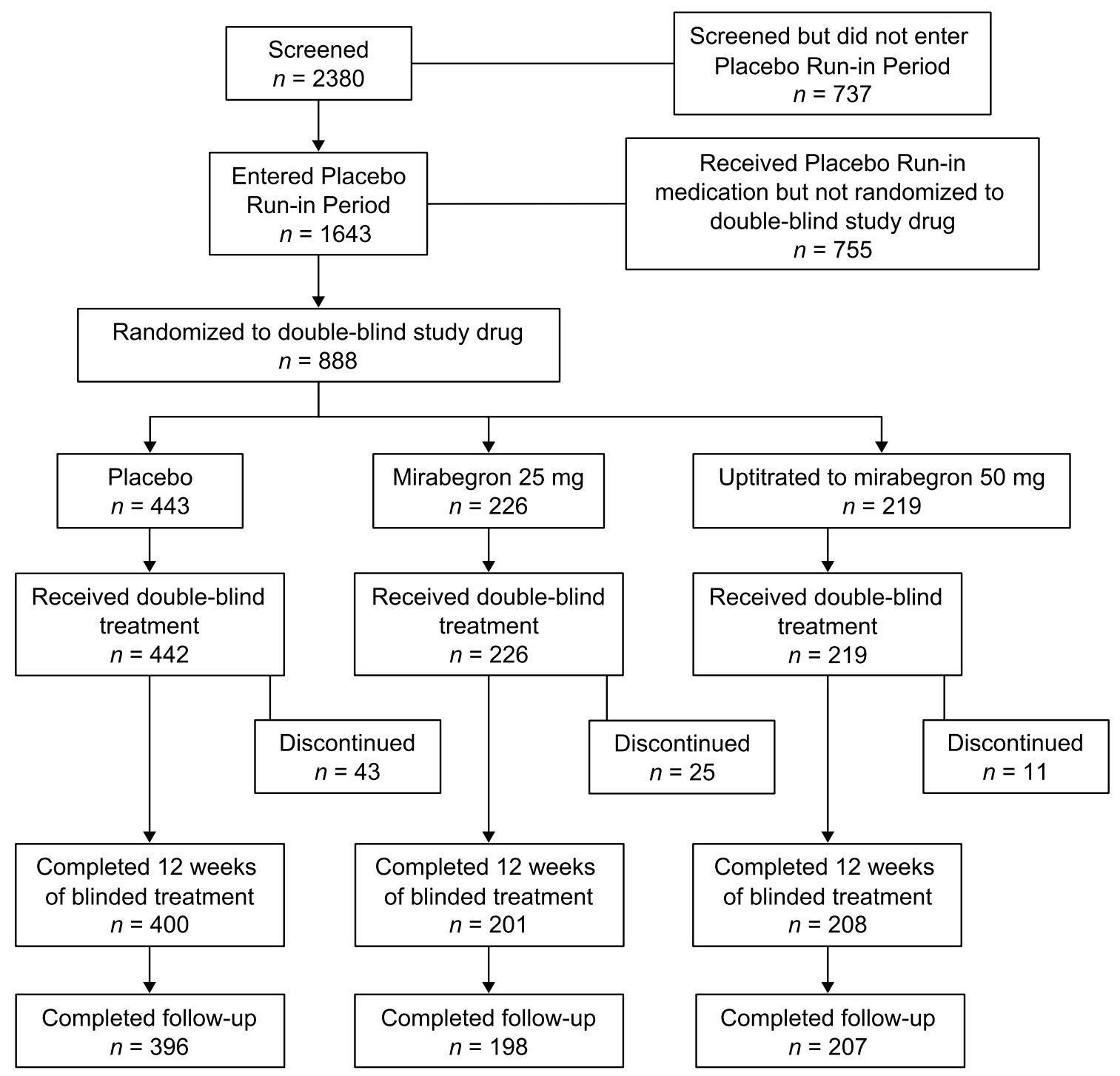

Fig. 1 Study flow chart

In terms of UTI, the proportion of patients experiencing a TEAE belonging to the composite UTI category (UTI, Escherichia UTI, UTI bacterial, and streptococcal UTI) was similar across treatment groups: $7.0 \%$ with placebo, $7.1 \%$ with mirabegron $25 \mathrm{mg}$, and $4.1 \%$ with mirabegron $50 \mathrm{mg}$. A TEAE in the category of urinary retention was reported for a similar proportion of patients (two receiving placebo and two receiving mirabegron). No cases required catheterization. No patients in any treatment group reported a TEAE of BPO.

\subsubsection{Vital Signs-Central Tendency over Time}

Adjusted mean change from baseline to EoT in SBP recorded during office visits was greatest in the placebo group $(0.80 \mathrm{mmHg}$; $95 \%$ confidence interval $[\mathrm{CI}]-0.78$ to 2.37$)$ and lowest in the mirabegron $25 \mathrm{mg}$ group $(0.25 \mathrm{mmHg}$; 95\% CI -1.76 to 2.26 ). From home-based monitoring, excluding extreme values, adjusted mean change from baseline to EoT in overall SBP (morning and afternoon measurements) was $-2.95 \mathrm{mmHg}(95 \% \mathrm{CI}-4.33$ to -1.58$)$ in the mirabegron $50 \mathrm{mg}$ group and $-1.76 \mathrm{mmHg}(95 \% \mathrm{CI}-2.94$ to -0.58$)$ in the placebo group.

For DBP, adjusted mean change from baseline to EoT from office visits was $-0.98 \mathrm{mmHg}(95 \% \mathrm{CI}-2.24$ to 0.27$)$ in the mirabegron $25 \mathrm{mg}$ group and $-0.05 \mathrm{mmHg}(95 \% \mathrm{CI}$ -1.18 to 1.09 ) in the mirabegron $50 \mathrm{mg}$ group. From homebased monitoring, excluding extreme values, adjusted mean change in overall DBP (morning and afternoon measurements) was $-1.71 \mathrm{mmHg}(95 \% \mathrm{CI}-2.62$ to -0.80$)$ in the mirabegron $50 \mathrm{mg}$ group and $-1.03 \mathrm{mmHg}(95 \% \mathrm{CI}-1.81$ to -0.25$)$ in the placebo group. 
Table 2 Treatment-emergent adverse events by age group $(<75, \geq 75$ years $)$ —safety analysis set

\begin{tabular}{|c|c|c|c|c|c|c|c|c|}
\hline \multirow[t]{2}{*}{ TEAEs $^{\mathrm{a}}$} & \multicolumn{2}{|c|}{ Placebo $(n=442)$} & \multicolumn{2}{|c|}{ Mirabegron $25 \mathrm{mg}(n=226)$} & \multicolumn{2}{|c|}{ Mirabegron $50 \mathrm{mg}(n=219)$} & \multicolumn{2}{|c|}{ Mirabegron total $(n=445)$} \\
\hline & $\begin{array}{l}<75 \text { years } \\
(n=318)\end{array}$ & $\begin{array}{l}\geq 75 \text { years } \\
(n=124)\end{array}$ & $\begin{array}{l}<75 \text { years } \\
(n=160)\end{array}$ & $\begin{array}{l}\geq 75 \text { years } \\
(n=66)\end{array}$ & $\begin{array}{l}<75 \text { years } \\
(n=160)\end{array}$ & $\begin{array}{l}\geq 75 \text { years } \\
(n=59)\end{array}$ & $\begin{array}{l}<75 \text { years } \\
(n=320)\end{array}$ & $\begin{array}{l}\geq 75 \text { years } \\
(n=125)\end{array}$ \\
\hline One or more TEAE & $125(39.3)$ & $49(39.5)$ & 65 (40.6) & $35(53.0)$ & $80(50.0)$ & $29(49.2)$ & $145(45.3)$ & $64(51.2)$ \\
\hline $\begin{array}{l}\text { Drug-related } \\
\text { TEAEs }^{\text {b }}\end{array}$ & $43(13.5)$ & $14(11.3)$ & $30(18.8)$ & $17(25.8)$ & $29(18.1)$ & $8(13.6)$ & $59(18.4)$ & $25(20.0)$ \\
\hline Serious TEAEs & $9(2.8)$ & $3(2.4)$ & $5(3.1)$ & $2(3.0)$ & $7(4.4)$ & $1(1.7)$ & $12(3.8)$ & $3(2.4)$ \\
\hline $\begin{array}{l}\text { Serious drug- } \\
\text { related TEAEs }\end{array}$ & $2(0.6)$ & 0 & 0 & 0 & 0 & 0 & 0 & 0 \\
\hline $\begin{array}{l}\text { TEAEs leading to } \\
\text { discontinuation }\end{array}$ & $6(1.9)$ & $8(6.5)$ & $6(3.8)$ & $2(3.0)$ & $4(2.5)$ & $2(3.4)$ & $10(3.1)$ & $4(3.2)$ \\
\hline $\begin{array}{l}\text { Drug-related } \\
\text { TEAEs } \\
\text { leading to } \\
\text { discontinuation }^{\mathrm{b}}\end{array}$ & $5(1.6)$ & $2(1.6)$ & $4(2.5)$ & $2(3.0)$ & $2(1.3)$ & $2(3.4)$ & $6(1.9)$ & $4(3.2)$ \\
\hline Cardiac disorders & $3(0.9)$ & $2(1.6)$ & $2(1.3)$ & 0 & $7(4.4)$ & 0 & $9(2.8)$ & 0 \\
\hline \multicolumn{9}{|c|}{ Most frequent TEAEs ${ }^{c}$} \\
\hline $\begin{array}{l}\text { Urinary tract } \\
\text { infection }^{\mathrm{d}}\end{array}$ & $21(6.6)$ & $10(8.1)$ & $11(6.9)$ & $5(7.6)$ & $5(3.1)$ & $4(6.8)$ & $16(5.0)$ & $9(7.2)$ \\
\hline Headache & $8(2.5)$ & $4(3.2)$ & $12(7.5)$ & $3(4.5)$ & $4(2.5)$ & $4(6.8)$ & $16(5.0)$ & $7(5.6)$ \\
\hline Diarrhea & $2(0.6)$ & $4(3.2)$ & $8(5.0)$ & $3(4.5)$ & $2(1.3)$ & 0 & $10(3.1)$ & $3(2.4)$ \\
\hline Fatigue & $8(2.5)$ & $6(4.8)$ & $3(1.9)$ & $3(4.5)$ & $3(1.9)$ & $1(1.7)$ & $6(1.9)$ & $4(3.2)$ \\
\hline $\begin{array}{l}\text { Upper respiratory } \\
\text { tract infection }\end{array}$ & $6(1.9)$ & $4(3.2)$ & $3(1.9)$ & 0 & $5(3.1)$ & $2(3.4)$ & $8(2.5)$ & $2(1.6)$ \\
\hline Nausea & $5(1.6)$ & $1(0.8)$ & $4(2.5)$ & $3(4.5)$ & $1(0.6)$ & 0 & $5(1.6)$ & $3(2.4)$ \\
\hline Dizziness & $7(2.2)$ & 0 & $1(0.6)$ & 0 & $5(3.1)$ & 0 & $6(1.9)$ & 0 \\
\hline Nasopharyngitis & $7(2.2)$ & $3(2.4)$ & $2(1.3)$ & $1(1.5)$ & $2(1.3)$ & 0 & $4(1.3)$ & $1(0.8)$ \\
\hline
\end{tabular}

Data are presented as $N(\%)$ unless otherwise indicated. MedDRA version 20.1. Safety analysis set: all randomized subjects who received one or more dose of study medication

TEAE treatment-emergent adverse event

${ }^{a}$ TEAEs are defined as adverse events that started or worsened in the period from first double-blind medication intake until 30 days after the last double-blind medication intake. The number of patients reporting an event are presented

${ }^{\mathrm{b}}$ Possible or probable, as assessed by the investigator, or where relationship was missing

${ }^{c}$ Preferred term; affecting $\geq 2 \%$ of any treatment group

${ }^{\mathrm{d}}$ Escherichia urinary tract infection, streptococcal urinary tract infection, urinary tract infection, or urinary tract infection bacterial

For pulse rate, adjusted mean change from baseline to EoT from office visits was greatest in the mirabegron $25 \mathrm{mg}$ group (-1.46 bpm; 95\% CI -2.79 to -0.14$)$ and lowest in the mirabegron $50 \mathrm{mg}$ group $(-0.84 \mathrm{bpm} ; 95 \% \mathrm{CI}-2.04$ to 0.36 ). From home-based monitoring, excluding extreme values, adjusted mean change from baseline to EoT in overall pulse rate (morning and afternoon measurements) was greatest in the mirabegron $25 \mathrm{mg}$ group $(-1.43 \mathrm{bpm}$; 95\% $\mathrm{CI}-2.42$ to -0.44$)$ and lowest in the mirabegron $50 \mathrm{mg}$ group ( $-0.81 \mathrm{bpm} ; 95 \% \mathrm{CI}-1.70$ to 0.08 ).

The incidence of potentially clinically significant (PCS) changes in vital signs from office visits was higher than from home-based monitoring (Table 4). No shifts from a baseline normal SBP or DBP to worst result (hypertension stage 2) during the double-blind treatment period were noted in patients in any treatment group for office visits or for home-based monitoring at any time point (Table 5). Shifts from a baseline normal DBP to worst result (hypertension stage 2) during the double-blind treatment period for homebased monitoring were noted in one patient in the placebo group and two in the mirabegron $25 \mathrm{mg}$ group for morning measurements, and for one patient in the mirabegron $50 \mathrm{mg}$ group who uptitrated at week 4 for afternoon measurements. Overall, shifts from baseline normal DBP to worst result during the double-blind treatment period were noted in two $(0.6 \%)$ and two $(1.2 \%)$ patients in the placebo and mirabegron $25 \mathrm{mg}$ groups, respectively. Shifts from a baseline pulse rate $\leq 100$ to $>100 \mathrm{bpm}$ during the double-blind treatment period for office visits were noted in three $(0.7 \%)$, two $(0.9 \%)$, and two $(0.9 \%)$ patients receiving placebo, mirabegron $25 \mathrm{mg}$, and mirabegron $50 \mathrm{mg}$, respectively; the shifts 


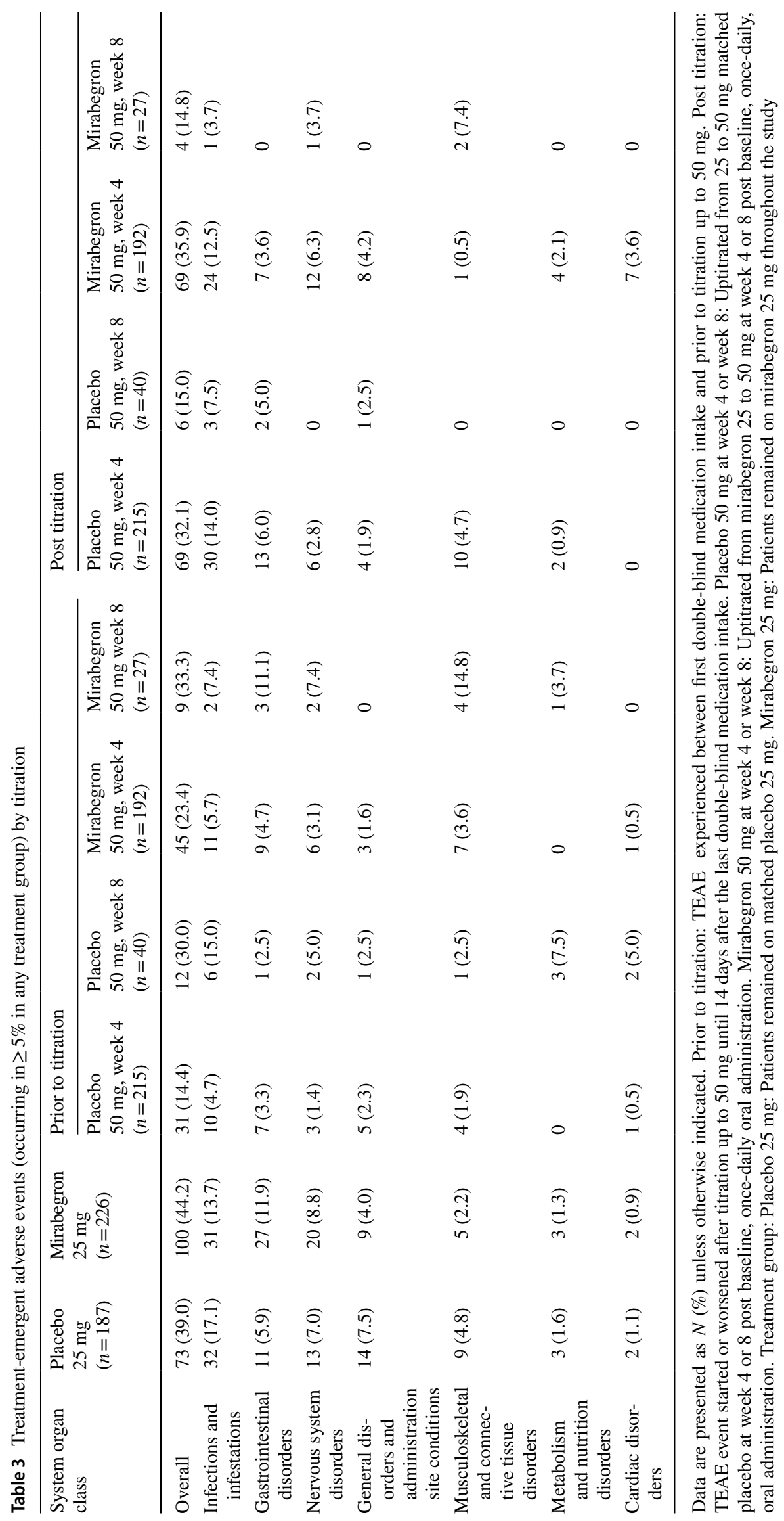


Table 4 Potentially clinically significant vital signs by age group $(<75, \geq 75$ years $)$ - Home-based and office visit measurements

\begin{tabular}{|c|c|c|c|c|c|c|c|c|c|}
\hline \multirow[t]{2}{*}{ Vital sign } & \multirow{2}{*}{$\begin{array}{l}\text { Increase } \\
\text { criteria }\end{array}$} & \multicolumn{2}{|c|}{ Placebo $(n=442)$} & \multicolumn{2}{|c|}{ Mirabegron $25 \mathrm{mg}(n=226)$} & \multicolumn{2}{|c|}{ Mirabegron $50 \mathrm{mg}(n=219)$} & \multicolumn{2}{|c|}{ Mirabegron total $(n=445)$} \\
\hline & & $\begin{array}{l}<75 \text { years } \\
(n=318)\end{array}$ & $\begin{array}{l}\geq 75 \text { years } \\
(n=124)\end{array}$ & $\begin{array}{l}<75 \text { years } \\
(n=160)\end{array}$ & $\begin{array}{l}\geq 75 \text { years } \\
(n=66)\end{array}$ & $\begin{array}{l}<75 \text { years } \\
(n=160)\end{array}$ & $\begin{array}{l}\geq 75 \text { years } \\
(n=59)\end{array}$ & $\begin{array}{l}<75 \text { years } \\
(n=320)\end{array}$ & $\begin{array}{l}\geq 75 \text { years } \\
(n=125)\end{array}$ \\
\hline \multicolumn{10}{|c|}{ Home-based (excluding extreme values) } \\
\hline \multirow[t]{3}{*}{$\mathrm{SBP}(\mathrm{mmHg})$} & $>10$ & $6 / 238(2.5)$ & $3 / 87(3.4)$ & $3 / 126(2.4)$ & 0 & $8 / 116(6.9)$ & $1 / 43(2.3)$ & $11 / 242(4.5)$ & $1 / 92(1.1)$ \\
\hline & $>15$ & 0 & $2 / 87(2.3)$ & $2 / 126(1.6)$ & 0 & $1 / 116(0.9)$ & 0 & $3 / 242(1.2)$ & 0 \\
\hline & $>20$ & 0 & 0 & 0 & 0 & 0 & 0 & 0 & 0 \\
\hline \multirow{3}{*}{$\begin{array}{l}\mathrm{DBP} \\
\quad(\mathrm{mmHg})\end{array}$} & $>5$ & $17 / 238(7.1)$ & $5 / 87(5.7)$ & $9 / 126(7.1)$ & $4 / 49(8.2)$ & $5 / 116(4.3)$ & $4 / 43(9.3)$ & $14 / 242(5.8)$ & $8 / 92(8.7)$ \\
\hline & $>10$ & $4 / 238(1.7)$ & $2 / 87(2.3)$ & $1 / 126(0.8)$ & $2 / 49(4.1)$ & $1 / 116(0.9)$ & $1 / 43(2.3)$ & $2 / 242(0.8)$ & $3 / 92(3.3)$ \\
\hline & $>15$ & 0 & 0 & 0 & 0 & 0 & 0 & 0 & 0 \\
\hline \multirow{3}{*}{$\begin{array}{l}\text { Pulse rate } \\
\quad \text { (bpm) }\end{array}$} & $>5$ & 17/237 (7.2) & $9 / 86(10.5)$ & $15 / 125(12.0)$ & $6 / 49(12.2)$ & $9 / 115(7.8)$ & $2 / 43(4.7)$ & $24 / 240(10.0)$ & 8/92 (8.7) \\
\hline & $>10$ & 0 & $1 / 86(1.2)$ & 0 & 0 & $1 / 115(0.9)$ & 0 & $1 / 240(0.4)$ & 0 \\
\hline & $>15$ & 0 & 0 & 0 & 0 & $1 / 115(0.9)$ & 0 & $1 / 240(0.4)$ & 0 \\
\hline \multicolumn{10}{|l|}{ Office visits } \\
\hline \multirow[t]{3}{*}{$\mathrm{SBP}(\mathrm{mmHg})$} & $>10$ & $31 / 312(9.9)$ & $18 / 121(14.9)$ & $9 / 158(5.7)$ & $9 / 66(13.6)$ & $20 / 160(12.5)$ & $11 / 59(18.6)$ & $29 / 318(9.1)$ & $20 / 125$ (16.0) \\
\hline & $>15$ & $12 / 312(3.8)$ & 14/121 (11.6) & $7 / 158(4.4)$ & $7 / 66(10.6)$ & $16 / 160(10.0)$ & $7 / 59$ (11.9) & $23 / 318(7.2)$ & $14 / 125(11.2)$ \\
\hline & $>20$ & 4/312 (1.3) & 8/121 (6.6) & $5 / 158(3.2)$ & $5 / 66(7.6)$ & $9 / 160(5.6)$ & $4 / 59(6.8)$ & $14 / 318(4.4)$ & $9 / 125(7.2)$ \\
\hline \multirow{3}{*}{$\begin{array}{l}\text { DBP } \\
\quad(\mathrm{mmHg})\end{array}$} & $>5$ & $37 / 312(11.9)$ & 18/121 (14.9) & $24 / 158(15.2)$ & $7 / 66(10.6)$ & $32 / 160(20.0)$ & $11 / 59(18.6)$ & $56 / 318(4.1)$ & $18 / 125(14.4)$ \\
\hline & $>10$ & $11 / 312(3.5)$ & $7 / 121(5.8)$ & $6 / 158$ (3.8) & $5 / 66(7.6)$ & $7 / 160(4.4)$ & $3 / 59(5.1)$ & $13 / 318(4.1)$ & $8 / 125(6.4)$ \\
\hline & $>15$ & $3 / 312(1.0)$ & 4/121 (3.3) & $2 / 158(1.3)$ & $3 / 66(4.5)$ & $1 / 160(0.6)$ & 0 & $3 / 318(0.9)$ & $3 / 125(2.4)$ \\
\hline \multirow{3}{*}{$\begin{array}{l}\text { Pulse rate } \\
\quad(\mathrm{bpm})\end{array}$} & $>5$ & $47 / 312(15.1)$ & $20 / 121(16.5)$ & $20 / 158(12.7)$ & $8 / 66(12.1)$ & $29 / 160(18.1)$ & $9 / 59(15.3)$ & $49 / 318(15.4)$ & $17 / 125(13.6)$ \\
\hline & $>10$ & $13 / 312(4.2)$ & 2/121 (1.7) & $5 / 158(3.2)$ & $4 / 66(6.1)$ & $10 / 160(6.3)$ & $5 / 59(8.5)$ & $15 / 318(4.7)$ & $9 / 125(7.2)$ \\
\hline & $>15$ & $6 / 312(1.9)$ & 1/121 (0.8) & 1/158 (0.6) & $1 / 66(1.5)$ & $5 / 160(3.1)$ & 0 & $6 / 318(1.9)$ & $1 / 125(0.8)$ \\
\hline
\end{tabular}

$D B P$ diastolic blood pressure, $S B P$ systolic blood pressure

Data are presented as $\mathrm{n} / \mathrm{N}(\%)$

$\mathrm{N}=$ number of patients with at least one non-missing value during treatment. Number and percentage of patients meeting each criteria on 2 consecutive post-baseline visits are summarized

were observed in patients who titrated up to mirabegron $50 \mathrm{mg}$ after week 4 .

\subsubsection{Other Safety Parameters}

Two patients in the placebo group had a clinically significant abnormal ECG at week 8 (right bundle branch block, inferior epicardial injury), and two patients in the mirabegron $50 \mathrm{mg}$ group had a clinically significant abnormal ECG at EoT (left bundle branch block, atrial fibrillation). Mean change from baseline to EoT in PVR volume was comparable for all treatments. Eight patients $(2.1 \%)$ in the placebo group and four in the mirabegron total group shifted from a PVR volume $<150 \mathrm{~mL}$ at baseline to $\geq 150 \mathrm{~mL}$ and $<300 \mathrm{~mL}$ at EoT. Two patients in the mirabegron group shifted from a PVR volume of $<150 \mathrm{~mL}$ at baseline to $\geq 300 \mathrm{~mL}$ at EoT.

\section{Discussion}

Mirabegron treatment was well-tolerated in older adults with OAB-wet. Safety and tolerability in this study of patients aged $\geq 65$ years were consistent with the known mirabegron safety profile [23]. Despite a mean of eight comorbid conditions and 6.5 concomitant medications at baseline, few SAEs were reported and only two (both in the placebo group) were considered drug related by the investigator; there were no mirabegron-related SAEs. The majority of TEAEs in all treatment groups were mild or moderate in severity.

The overall frequency of mirabegron TEAEs in this study (47.0\%) was similar to that previously reported in patients aged $\geq 65$ years enrolled in phase III studies (mirabegron $25 \mathrm{mg}, 54.5 \%$; mirabegron $50 \mathrm{mg}, 50.2 \%$ ) [13]. Additionally, the most frequently reported TEAEs (UTI, headache, and diarrhea) were consistent with the known safety profile of mirabegron [23].

In PILLAR, TEAEs did not appear to be either dose or age related, and the majority were reported early following medication exposure. An increase in dose did not appear to precipitate an increase in AE reporting (Table 3). Interestingly, the people who titrated up to $50 \mathrm{mg}$ appeared fundamentally different: prior to titration, the incidence of TEAEs for these patients was higher in both the placebo and the mirabegron $50 \mathrm{mg}$ groups. In addition, there were also baseline differences in weight, body mass index category, race, and $\mathrm{OAB}$ severity that may have been associated with the choice of uptitration. Reporting of TEAEs may be related to 
Table 5 Shift table for systolic and diastolic blood pressure during the double-blind treatment period (measured during office visits)

\begin{tabular}{|c|c|c|c|c|c|c|}
\hline \multirow{2}{*}{$\begin{array}{l}\text { Systolic and diastolic blood } \\
\text { pressure and study drug }\end{array}$} & \multirow[t]{2}{*}{ Post-baseline } & \multicolumn{5}{|l|}{ Baseline } \\
\hline & & Normal & Prehypertension & Hypertension stage 1 & Hypertension stage 2 & Total \\
\hline \multicolumn{7}{|l|}{ Systolic blood pressure } \\
\hline \multirow[t]{6}{*}{ Placebo } & Normal & $36(8.4)$ & $13(3.0)$ & 0 & 0 & 49 \\
\hline & Prehypertension & $66(15.3)$ & 149 (34.6) & $18(4.2)$ & $2(0.5)$ & 235 \\
\hline & Hypertension stage 1 & $11(2.6)$ & $65(15.1)$ & $50(11.6)$ & $5(1.2)$ & 131 \\
\hline & Hypertension stage 2 & 0 & $4(0.9)$ & $10(2.3)$ & $2(0.5)$ & 16 \\
\hline & Total & 113 & 231 & 78 & 9 & 431 \\
\hline & No data & 2 & 5 & 3 & 1 & 11 \\
\hline \multirow[t]{6}{*}{ Mirabegron $25 \mathrm{mg}$} & Normal & $11(4.9)$ & $6(2.7)$ & 0 & 0 & 17 \\
\hline & Prehypertension & $33(14.7)$ & $92(41.1)$ & $11(4.9)$ & 0 & 136 \\
\hline & Hypertension stage 1 & $8(3.6)$ & $31(13.8)$ & $21(9.4)$ & $2(0.9)$ & 62 \\
\hline & Hypertension stage 2 & 0 & $3(1.3)$ & $3(1.3)$ & $3(1.3)$ & 9 \\
\hline & Total & 52 & 132 & 35 & 5 & 224 \\
\hline & No data & 1 & 1 & 0 & 0 & 2 \\
\hline \multirow{6}{*}{$\begin{array}{l}\text { Mirabegron } 50 \mathrm{mg} \\
\text { titration at week } 4\end{array}$} & Normal & $22(11.5)$ & $6(3.1)$ & 0 & 0 & 28 \\
\hline & Prehypertension & $24(12.5)$ & $38(19.8)$ & $18(9.4)$ & 0 & 80 \\
\hline & Hypertension stage 1 & $13(6.8)$ & $32(16.7)$ & $27(14.1)$ & $1(0.5)$ & 73 \\
\hline & Hypertension stage 2 & 0 & $2(1.0)$ & $9(4.7)$ & 0 & 11 \\
\hline & Total & 59 & 78 & 54 & 1 & 192 \\
\hline & No data & 0 & 0 & 0 & 0 & 0 \\
\hline \multirow{6}{*}{$\begin{array}{l}\text { Mirabegron } 50 \mathrm{mg} \\
\text { titration at week } 8\end{array}$} & Normal & $2(7.4)$ & $1(3.7)$ & 0 & 0 & 3 \\
\hline & Prehypertension & $3(11.1)$ & $9(33.3)$ & $1(3.7)$ & 0 & 13 \\
\hline & Hypertension stage 1 & $1(3.7)$ & $2(7.4)$ & $3(11.1)$ & $2(7.4)$ & 8 \\
\hline & Hypertension stage 2 & 0 & 0 & $1(3.7)$ & $2(7.4)$ & 3 \\
\hline & Total & 6 & 12 & 5 & 4 & 27 \\
\hline & No data & 0 & 0 & 0 & 0 & 0 \\
\hline \multirow[t]{6}{*}{ Mirabegron $50 \mathrm{mg}$} & Normal & $24(11.0)$ & $7(3.2)$ & 0 & 0 & 31 \\
\hline & Prehypertension & $27(12.3)$ & $47(21.5)$ & $19(8.7)$ & 0 & 93 \\
\hline & Hypertension stage 1 & $14(6.4)$ & $34(15.5)$ & $30(13.7)$ & $3(1.4)$ & 81 \\
\hline & Hypertension stage 2 & 0 & $2(0.9)$ & $10(4.6)$ & $2(0.9)$ & 14 \\
\hline & Total & 65 & 90 & 59 & 5 & 219 \\
\hline & No data & 0 & 0 & 0 & 0 & 0 \\
\hline \multicolumn{7}{|l|}{ Diastolic blood pressure } \\
\hline \multirow[t]{6}{*}{ Placebo } & Normal & $217(50.2)$ & $25(5.8)$ & $2(0.5)$ & 0 & 244 \\
\hline & Prehypertension & $78(18.1)$ & $57(13.2)$ & $7(1.6)$ & $1(0.2)$ & 143 \\
\hline & Hypertension stage 1 & $18(4.2)$ & $21(4.9)$ & $5(1.2)$ & $1(0.2)$ & 45 \\
\hline & Hypertension stage 2 & 0 & 0 & 0 & 0 & 0 \\
\hline & Total & 313 & 103 & 14 & 2 & 432 \\
\hline & No data & 8 & 2 & 0 & 0 & 10 \\
\hline \multirow[t]{6}{*}{ Mirabegron $25 \mathrm{mg}$} & Normal & $118(52.7)$ & $20(8.9)$ & $1(0.4)$ & 0 & 139 \\
\hline & Prehypertension & $41(18.3)$ & $20(8.9)$ & $2(0.9)$ & $1(0.4)$ & 64 \\
\hline & Hypertension stage 1 & $8(3.6)$ & $8(3.6)$ & $3(1.3)$ & 0 & 19 \\
\hline & Hypertension stage 2 & 0 & $1(0.4)$ & 0 & $1(0.4)$ & 2 \\
\hline & Total & 167 & 49 & 6 & 2 & 224 \\
\hline & No data & 1 & 1 & 0 & 0 & 2 \\
\hline
\end{tabular}


Table 5 (continued)

\begin{tabular}{|c|c|c|c|c|c|c|}
\hline \multirow{2}{*}{$\begin{array}{l}\text { Systolic and diastolic blood } \\
\text { pressure and study drug }\end{array}$} & \multirow[t]{2}{*}{ Post-baseline } & \multicolumn{5}{|l|}{ Baseline } \\
\hline & & Normal & Prehypertension & Hypertension stage 1 & Hypertension stage 2 & Total \\
\hline \multirow{6}{*}{$\begin{array}{l}\text { Mirabegron } 50 \mathrm{mg} \text { titration } \\
\text { at week } 4\end{array}$} & Normal & $75(39.1)$ & $11(5.7)$ & 0 & 0 & 86 \\
\hline & Prehypertension & $41(21.4)$ & $35(18.2)$ & $6(3.1)$ & $1(0.5)$ & 83 \\
\hline & Hypertension stage 1 & $7(3.6)$ & $10(5.2)$ & $5(2.6)$ & 0 & 22 \\
\hline & Hypertension stage 2 & 0 & 0 & $1(0.5)$ & 0 & 1 \\
\hline & Total & 123 & 56 & 12 & 1 & 192 \\
\hline & No data & 0 & 0 & 0 & 0 & 0 \\
\hline \multirow{6}{*}{$\begin{array}{l}\text { Mirabegron } 50 \mathrm{mg} \text { titration } \\
\text { at week } 8\end{array}$} & Normal & $10(37.0)$ & $2(7.4)$ & 0 & 0 & 12 \\
\hline & Prehypertension & $6(22.2)$ & 7 (25.9) & 0 & 0 & 13 \\
\hline & Hypertension stage 1 & $1(3.7)$ & $1(3.7)$ & 0 & 0 & 2 \\
\hline & Hypertension stage 2 & 0 & 0 & 0 & 0 & 0 \\
\hline & Total & 17 & 10 & 0 & 0 & 27 \\
\hline & No data & 0 & 0 & 0 & 0 & 0 \\
\hline \multirow[t]{6}{*}{ Mirabegron $50 \mathrm{mg}$} & Normal & $85(38.8)$ & $13(5.9)$ & 0 & 0 & 98 \\
\hline & Prehypertension & $47(21.5)$ & $42(19.2)$ & $6(2.7)$ & $1(0.5)$ & 96 \\
\hline & Hypertension stage 1 & $8(3.7)$ & $11(5.0)$ & $5(2.3)$ & 0 & 24 \\
\hline & Hypertension stage 2 & 0 & 0 & $1(0.5)$ & 0 & 1 \\
\hline & Total & 140 & 66 & 12 & 1 & 219 \\
\hline & No data & 0 & 0 & 0 & 0 & 0 \\
\hline
\end{tabular}

Data are presented as $N(\%)$

inefficacy; studies of fesoterodine have shown that patients experiencing greater efficacy are less likely to report TEAEs than those experiencing less efficacy [24].

Few patients met the criteria for PCS laboratory values, with no relevant differences across treatment groups. There were no clinically meaningful differences in changes in vital signs from baseline to EoT for any treatment group, and no differences were observed between the mirabegron and placebo treatment groups.

As shown in Table 4, for home-based monitoring, the incidence of PCS increases of SBP (>10 mmHg), excluding extreme values, was slightly higher in the mirabegron $50 \mathrm{mg}$ group than in the placebo and mirabegron $25 \mathrm{mg}$ groups, and the incidence of PCS increases of DBP $(>5 \mathrm{mmHg}$ ) was slightly higher in the mirabegron $25 \mathrm{mg}$ group than in the other groups. Incidences of increases of $>15 \mathrm{mmHg}$ for SBP and of $>10 \mathrm{mmHg}$ for DBP were low and similar in all treatment groups. PCS increases of $>5 \mathrm{bpm}$ in pulse rate were slightly more frequent only in the mirabegron $25 \mathrm{mg}$ group versus the other groups, suggesting that these observations may not be due to any true effect.

For office-based monitoring, the incidence of PCS increases of SBP ( $>10$ and $>15 \mathrm{mmHg}$ ) was slightly higher in the mirabegron $50 \mathrm{mg}$ group than in the other groups. The incidence of PCS increases of DBP ( $>5 \mathrm{mmHg}$ ) was slightly higher in the mirabegron $50 \mathrm{mg}$ group than in the other groups. The incidence of increases of $>10 \mathrm{mmHg}$ for DBP was low and similar in all treatment groups. Increases of $>5 \mathrm{bpm}$ in pulse rate were slightly less frequent in the mirabegron $25 \mathrm{mg}$ group than in the other groups.

Overall, the incidence of PCS vital signs from office visits was slightly higher than from home-based monitoring, possibly due to white coat hypertension.

The mirabegron pivotal studies used the same definition for recording an $\mathrm{AE}$ of hypertension as was used in this study and similarly reported only small differences versus the placebo arms [16]. When the safety set for the pooled population from these pivotal studies ( $n=4611$ patients) was examined, mirabegron $50 \mathrm{mg} /$ day was associated with a mean increase of $\leq 1 \mathrm{mmHg}$ in blood pressure versus placebo, and the incidence of hypertension was similar between the total mirabegron, placebo, and tolterodine extended release $4 \mathrm{mg}$ groups [16]. In addition, the change in mean pulse rate for mirabegron was approximately $1 \mathrm{bpm}$ (clinically insignificant) compared with placebo and was reversible upon treatment discontinuation. The incidence of urinary retention was greater in the placebo and tolterodine groups than in mirabegron-treated patients, and ECG, PVR volume, and laboratory data were unremarkable across each treatment group [16].

Strengths of the current study include its randomized controlled design and that there were few exclusion criteria, 
with the aim of including as wide a range of older people as possible. Since patients aged $\geq 65$ years are often under-represented in clinical trials, results from this older population, including a significant number of patients aged $\geq 75$ years, are clinically relevant. Despite this, a relatively high number of patients failed to meet trial criteria after the placebo run-in period. From the diary variables, the majority failed on the urgency episode criterion. Other limitations of this study are that the study duration was only 12 weeks, and the characteristics of the sample may not be representative of all older patients with $\mathrm{OAB}$, although, as previously noted, the overall frequency of mirabegron TEAEs in this study was similar to that in patients aged $\geq 65$ years enrolled in phase III studies [13]. In addition, because knowledge about prior treatment exposure was lacking, there may have been a systematic reduction in TEAE reporting, although it should be noted that there was a treatment-free run-in period and that the rates of TEAE were roughly equivalent to those in previous trials including older patients $[8,25,26]$. Although the incidence of TEAEs in older patients was numerically higher than in younger patients, this was not associated with an increased number of withdrawals.

\section{Conclusions}

Mirabegron treatment was well-tolerated in older adults with OAB. Safety and tolerability were consistent with the known mirabegron safety profile.

The findings reported here provide further evidence for the overall safety and tolerability profile for mirabegron in patients aged $\geq 65$ years with OAB-wet. PILLAR provides data from a dedicated study in a population that is often under-represented in clinical trials despite the increasing prevalence of both the condition and the risk of AEs with older age.

Acknowledgements The authors thank the PILLAR study investigators and all patients and their parents/legal representatives who took part in the study.

\section{Compliance with Ethical Standards}

Funding This study was funded by Astellas Pharma Global Development, Inc. Medical writing support was provided by Sue Cooper, CMPP, and Catherine Elliott of Envision Scientific Solutions and funded by Astellas Pharma Global Development.

Conflict of interest Sender Herschorn has received grants from Astellas, Urovant, and Allergan and personal fees from Astellas and Pfizer. David Staskin has received grants and personal fees for services as an investigator, consultant, and speaker for Astellas. Carol R. Schermer and Rita M. Kristy are employees of Astellas Pharma Global Development, Inc. Adrian Wagg has received grants, personal fees, and other non-financial support from Astellas, Essity, Pfizer, and Pierre Fabre.
Ethical Approval Institutional review board/independent ethics committee-approved written informed consent was obtained from all participants or their legally authorized representative before any studyrelated procedures were carried out.

Data Sharing Researchers may request access to anonymized participant-level data, trial-level data, and protocols from Astellas-sponsored clinical trials at http://www.clinicalstudydatarequest.com. For the Astellas criteria on data sharing, see https://clinicalstudydatarequest. com/Study-Sponsors/Study-Sponsors-Astellas.aspx.

Open Access This article is licensed under a Creative Commons Attribution-NonCommercial 4.0 International License, which permits any non-commercial use, sharing, adaptation, distribution and reproduction in any medium or format, as long as you give appropriate credit to the original author(s) and the source, provide a link to the Creative Commons licence, and indicate if changes were made. The images or other third party material in this article are included in the article's Creative Commons licence, unless indicated otherwise in a credit line to the material. If material is not included in the article's Creative Commons licence and your intended use is not permitted by statutory regulation or exceeds the permitted use, you will need to obtain permission directly from the copyright holder. To view a copy of this licence, visit http://creativecommons.org/licenses/by-nc/4.0/.

\section{References}

1. Stewart WF, Van Rooyen JB, Cundiff GW, Abrams P, Herzog AR, Corey R, et al. Prevalence and burden of overactive bladder in the United States. World J Urol. 2003;20(6):327-36.

2. Milsom I, Stewart W, Thuroff J. The prevalence of overactive bladder. Am J Manag Care. 2000;6(11 Suppl):S565-73.

3. Irwin DE, Milsom I, Hunskaar S, Reilly K, Kopp Z, Herschorn S, et al. Population-based survey of urinary incontinence, overactive bladder, and other lower urinary tract symptoms in five countries: results of the EPIC study. Eur Urol. 2006;50(6):1306-14 discussion 14-5.

4. Coyne KS, Sexton CC, Thompson CL, Milsom I, Irwin D, Kopp ZS, et al. The prevalence of lower urinary tract symptoms (LUTS) in the USA, the UK and Sweden: results from the Epidemiology of LUTS (EpiLUTS) study. BJU Int. 2009;104(3):352-60.

5. Wagg A. Choosing oral drug therapy for overactive bladder in older people. Expert Opin Pharmacother. 2018;19(12):1375-80.

6. Chapple C, DuBeau C, Ebinger U, Rekeda L, Viegas A. Darifenacin treatment of patients $>$ or $=65$ years with overactive bladder: results of a randomized, controlled, 12-week trial. Curr Med Res Opin. 2007;23(10):2347-58.

7. Dubeau CE, Kraus SR, Griebling TL, Newman DK, Wyman JF, Johnson TM 2nd, et al. Effect of fesoterodine in vulnerable elderly subjects with urgency incontinence: a double-blind, placebo controlled trial. J Urol. 2014;191(2):395-404.

8. Wagg A, Nitti VW, Kelleher C, Castro-Diaz D, Siddiqui E, Berner T. Oral pharmacotherapy for overactive bladder in older patients: mirabegron as a potential alternative to antimuscarinics. Curr Med Res Opin. 2016;32(4):621-38.

9. Ganz ML, Liu J, Zou KH, Bhagnani T, Luo X. Real-world characteristics of elderly patients with overactive bladder in the United States. Curr Med Res Opin. 2016;32(12):1997-2005.

10. Kachru N, Sura S, Chatterjee S, Aparasu RR. Antimuscarinic medication use in elderly patients with overactive bladder. Drugs Aging. 2016;33(10):755-63.

11. Welk BM, McArthur E. Increased risk of dementia among patients with overactive bladder treated with an anticholinergic medication 
compared to a beta-3 agonist: a population-based cohort study. BJU Int. 2020;126(1):183-90.

12. Drake MJ, Chapple C, Esen AA, Athanasiou S, Cambronero J, Mitcheson D, et al. Efficacy and safety of mirabegron add-on therapy to solifenacin in incontinent overactive bladder patients with an inadequate response to initial 4-week solifenacin monotherapy: a randomised double-blind multicentre phase 3B study (BESIDE). Eur Urol. 2016;70(1):136-45.

13. Wagg A, Cardozo L, Nitti VW, Castro-Diaz D, Auerbach S, Blauwet MB, et al. The efficacy and tolerability of the beta3-adrenoceptor agonist mirabegron for the treatment of symptoms of overactive bladder in older patients. Age Ageing. 2014;43(5):666-75.

14. Yoshida M, Nozawa Y, Kato D, Tabuchi H, Kuroishi K. Safety and effectiveness of mirabegron in patients with overactive bladder aged $\geq 75$ years: analysis of a Japanese post-marketing study. Low Urin Tract Symptoms. 2019;11(1):30-8.

15. Herschorn S, Barkin J, Castro-Diaz D, Frankel JM, Espuna-Pons $\mathrm{M}$, Gousse AE, et al. A phase III, randomized, double-blind, parallel-group, placebo-controlled, multicentre study to assess the efficacy and safety of the beta(3) adrenoceptor agonist, mirabegron, in patients with symptoms of overactive bladder. Urology. 2013;82(2):313-20.

16. Nitti VW, Khullar V, van Kerrebroeck P, Herschorn S, Cambronero J, Angulo JC, et al. Mirabegron for the treatment of overactive bladder: a prespecified pooled efficacy analysis and pooled safety analysis of three randomised, double-blind, placebo-controlled, phase III studies. Int J Clin Pract. 2013;67(7):619-32.

17. Burkhard FC, Bosch JLHR, Cruz F, Lemack GE, Nambiar AK, Thiruchelvam N, et al. EAU urinary incontinence guidelines 2020. https://uroweb.org/guideline/urinary-incontinence/. Accessed 01 May 2020.

18. Gormley EA, Lightner DJ, Burgio KL, Chai TC, Clemens JQ, Culkin DJ, et al. Diagnosis and treatment of non-neurogenic overactive bladder (OAB) in adults: an AUA/SUFU guideline (2019). https://www.auanet.org/guidelines/overactive-bladder-(oab)-guide line. Accessed 01 May 2020.
19. Wagg A, Staskin D, Engel E, Herschorn S, Kristy RM, Schermer CR. Efficacy, safety, and tolerability of mirabegron in patients aged $\geq 65$ yr with overactive bladder wet: a phase IV, doubleblind, randomised, placebo-controlled study (PILLAR). Eur Urol. 2020;77(2):211-20.

20. Andersson KE, Sarawate C, Kahler KH, Stanley EL, Kulkarni AS. Cardiovascular morbidity, heart rates and use of antimuscarinics in patients with overactive bladder. BJU Int. 2010;106(2):268-74.

21. ICH. Introductory Guide. MedDRA Version 20.1. https://www. meddra.org/sites/default/files/guidance/file/intguide_20_1_engli sh_0.pdf. Accessed 10 Mar 2020.

22. Griebling TL, Campbell NL, Mangel J, Staskin D, Herschorn S, Elsouda D, et al. Effect of mirabegron on cognitive function in elderly patients with overactive bladder: MoCA results from a phase 4 randomized, placebo-controlled study (PILLAR). BMC Geriatr. 2020;20(1):109.

23. Astellas Pharma US, Inc. Prescribing information: MYRBETRIQ (mirabegron extended-release tablets). https://www.us.astellas. com/docs/Myrbetriq_WPI.pdf.

24. Wagg A, LaBossiere JR, Oelke M, Fernet M., Carlsson M, Herschorn S. How common are adverse events in patients with either a 50 or $100 \%$ resolution of $\mathrm{OAB}$ symptoms during treatment with fesoterodine? Poster presented at: ICS 2018; August 29, 2018; Philadelphia, PA, USA. https://www.ics.org/2018/abstract/152.

25. Chapple CR, Cruz F, Cardozo L, Staskin D, Herschorn S, Choudhury N, et al. Safety and efficacy of mirabegron: analysis of a large integrated clinical trial database of patients with overactive bladder receiving mirabegron, antimuscarinics, or placebo. Eur Urol. 2020;77(1):119-28.

26. Foley S, Choudhury N, Huang M, Stari A, Nazir J, Freeman R. Quality of life in patients aged 65 years and older with overactive bladder treated with mirabegron across eight European countries: secondary analysis of BELIEVE. Int J Urol. 2019;26(9):890-6. 